Article

\title{
Simultaneous In-Cylinder Flow Measurement and Flame Imaging in a Realistic Operating Engine Environment Using High-Speed PIV
}

\author{
Atsushi Nishiyama *, Minh Khoi Le, Takashi Furui and Yuji Ikeda \\ Imagineering, Inc., 7-4-4 Minatojima-Minami, Chuo, Kobe 650-0047, Japan \\ * Correspondence: atsushi@imagineering.jp; Tel.: +81-78-386-8888
}

Received: 11 March 2019; Accepted: 18 April 2019; Published: 30 June 2019

\begin{abstract}
Among multiple factors that affect the quality of combustion, the intricate and complex interaction between in-cylinder flow/turbulent field and flame propagation is one of the most important. In this study, true simultaneous, crank-angle resolved imaging of the flame front propagation and the measurement of flow-field was achieved by the application of high-speed Particle Image Velocimetry (PIV). The technique was successfully implemented to avoid problems commonly associated with PIV in a combustion environment, such as interferences and reflections, avoided thanks to a number of adjustments and arrangements. All experiments were carried out inside a single-cylinder optical gasoline engine operated at $1200 \mathrm{rpm}$, using port fuel injection (PFI) with stoichiometric mixtures. It was found that the global vortex location of the tumble motion heavily influences the flame growth direction as well as the flame shape, mainly due to the tumble-induced flow across the ignition source. The flame propagation also influences the flow-field such that the pre-ignition flow can be maintained and the flow of unburned region surrounding the flame front will be enhanced.
\end{abstract}

Keywords: High speed PIV; flame propagation; planer laser tomography

\section{Introduction}

The current stringent emissions regulations as well as demands for better fuel economy in passenger vehicles require the combustion process in engines to be much more efficient while being cleaner overall. While other mode of powertrain such as electric or hybrid are developing, their drawbacks mean the combustion engines will still need to be improved. Researchers have proposed many approaches in order to achieve cleaner, more efficient combustion engines, including ultra-lean burning, high compression ratio, high exhaust gas recirculation (EGR), high intake charge pressure and others. Due to its strong effect on the overall combustion process and the complex in-cylinder turbulent environment [1-3], understanding the interaction of in-cylinder flow-field and flame development will be crucial in optimizing the effects of the aforementioned strategies.

Due to its importance and their intricate relationships, researchers have been working toward imaging both flow-field and flame imaging simultaneously. Flow-field measurement techniques have been quite well studied and developed, with diagnostics such as (Particle Image Velocimetry) PIV, (Laser Doppler Velocimetry) LDV and their variations providing useful information for engine researchers. LDV is a point-based measurement technique that provides the temporal flow velocity variations at a high sampling rate. Due to its setup, it is possible for a small probe of LDV to be made and applied to a production engine. For instance, special spark plug modified to contain LDV optics has been made and applied by engine researchers to provide flow-field information near the discharge location [4,5]. Despite its benefits, LDV cannot provide the important spatial information of in-cylinder flow, which is where PIV excels. In recent time, the advances in laser development has made powerful, 
high frequency laser available for researchers. Hence, PIV can now be applied to not just capture spatial characteristics of the in-cylinder flow but also its temporal evolution and development [6-8].

Most of the previous works about in-cylinder flow diagnostics of internal combustion engines were performed under motoring condition without combustion by using optical engines. However, the phenomenon in a practical engine is different from this condition. Figure 1 shows the phenomena of flow-field, flame propagation and its interaction in a spark ignition engine. During intake and compression stroke before ignition, the differences in flow-field between motoring and firing condition need to be discuss. For firing case, residual gas exists and its effect on flow-field, such as mean flow, turbulence intensity and scale, as well as cyclic variation should be investigated. After the ignition timing, one of the most interesting topics is the effect of flow-field on spark discharge, flame propagation speed, heat release and combustion duration. The large-scale flow will stretch the spark discharge and shift the propagating flame. The small-scale vortex will affect flame configuration and reaction zone thickness. The correlation between flow-field and flame propagation in the same cycle can provide the clear indication of the optimum velocity and turbulence distribution in-cylinder to realize faster flame propagation and combustion. As a result, detail analysis in these areas can provide valuable information for engine design to improve the thermal efficiency. Another point of interest is the effect of flame propagation on the flow-field in unburned mixture. Does the flame enhance or decay the turbulence of unburned mixture? Enhancement in the understanding of physical phenomena and accuracy of engine combustion simulations can be obtained from such results. Furthermore, heat loss is the one of the more important issues for thermal efficiency improvement and the information regarding on flame attachment to the wall as well as the corresponding velocity can help explain the heat transfer between flame wall (surface of piston top and cylinder head). The additional information in relation to the flame-wall interaction process can also be derived when using with advanced wall thermometry technique [9].

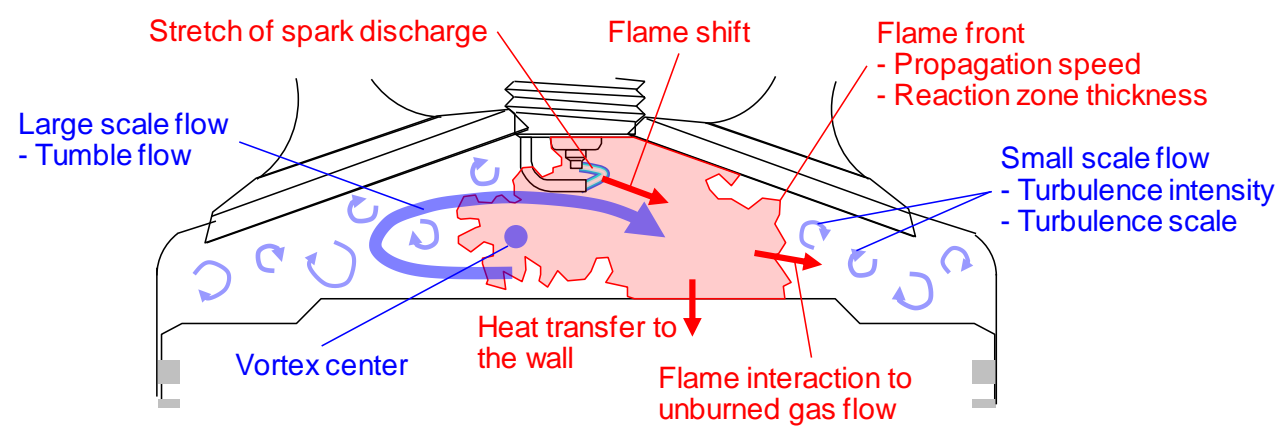

Figure 1. Flow-field, flame propagation, and its interaction in a spark ignition engine.

There are a number of diagnostics that one can use to observe the flame, ranging from simple natural emission based such as chemiluminescence or natural-flame luminosity to more complicated techniques such as tomography of hydroxyl planar laser-induced fluorescence (OH PLIF). Clark et al. investigated the effect of the timing of the first and second injection for an evenly split dual injection strategy in an optical engine [10,11]. Performance parameters derived from in-cylinder pressure data are analyzed alongside high-speed natural flame luminescence images in order to obtain relationships between engine output and the physical properties associated with flame propagation. They have been combined with PIV in attempts to observe flame and flow-field simultaneously and allow for interesting behaviors to be observed [12-14]. For instance, Mounaïm-Rousselle [13] used oil seeds for PIV that would be evaporated by the flame and hence, creating flame tomography effect to observe the flame. While this provide some information on the flame growth, it was not combined with flow-field and PIV results and the flow-field inside the burned region is missing. Other approaches involve the combination of laser diagnostic techniques: PIV and OH PLIF where there would be multiple cameras and lasers required to be implemented [12]. As OH PLIF is one of the best diagnostics for 
flame front, this set up has high accuracy and allows for derivation of more fundamental parameters such as turbulent burning velocity. However, OH PLIF is difficult to get enough signal intensity at high-speed to detect the change during the cycle.

In this study, true simultaneous, crank-angle resolved imaging of the flame front propagation, and the measurement of flow-field was achieved by the application of high-speed Particle Image Velocimetry (PIV). PIV measurement under combustion environment is quite challenging for multiple reasons, including the interferences of the natural luminosity from the flame, the interaction between the PIV seeding materials, and the high temperature flame, as well as complications from direct injection operations. All these issues decrease the optical clarity necessary for successful implementation of PIV. This is also why it is difficult to be able to observe both the flame and flow-field simultaneously in a reacting engine environment. Through careful optimization of a high-speed PIV setup and small modification of our engines, we have been able to observe simultaneously the flame and flow-field inside an operating engine environment. From the same captured PIV images, flow-field information as well as flame characteristics can be processed through a series of commercially-available and inhouse-developed software. The setup has been demonstrated to be able to capture the results at various engine operating conditions and provide valuable information on the relationship of flame development and in-cylinder flow [15]. In this report, we will discuss with more details on the setup, accuracy of the results and its potential errors. Focus will also be placed on the differences between the flow-field of non-reacting and reacting engine environment as well as the cyclic reaction on flame movement and combustion quality with respect to the flow-field.

\section{Materials and Methods}

\subsection{Engine Specifications and Operating Conditions}

The experiments were carried out in a single-cylinder optical spark ignition engine. Table 1 summarizes the specification of this engine and the selected operating condition for this study. The engine capacity is $500 \mathrm{~cm}^{3}$ and has a compression ratio of 10.4 with a bore of $86 \mathrm{~mm}$ and stroke of $86 \mathrm{~mm}$. Optical access into the combustion chamber of the engine is provided by replacing certain metal parts with quartz window: at the top of the piston (54 mm diameter) and in the pent-roof as shown in Figure 2a. The whole metal liner can be replaced by quartz for extended optical view into the chamber. To observe the bottom-view of the combustion chamber, a $45^{\circ}$ mirror is placed in the hollow extended-piston. It also provides an optical-access path for laser for the observation of pent-roof area, which is the setup applied for this study. The experiments were carried out with the engine operating at $1200 \mathrm{rpm}$ with port fuel injection and an absolute intake pressure of $60 \mathrm{kPa}$. The spark timing was set at $-15^{\circ}$ Crank-Angle after Top Dead Center (CA aTDC). Due to the focus of this study, only mixture at stoichiometry will be considered. In-cylinder pressure are monitored and recorded using a pressure transducer (Kistler, 6052C) and the engine is fired continuously during the PIV capturing process for synchronization purpose.

Table 1. Engine specifications and test conditions. PFI: port fuel injection; CA aTDC: Crank-Angle after Top Dead Center.

\begin{tabular}{cc}
\hline Engine Type & 4 Stroke, Single Cylinder, PFI \\
\hline Bore $\times$ stroke & $86 \times 86 \mathrm{~mm}$ \\
Displacement & $500 \mathrm{~cm}^{3}$ \\
Compression ratio & 10.4 \\
Fuel injection & Port fuel injection \\
Fuel type & Regular gasoline \\
Injection pressure & $300 \mathrm{kPa}$ \\
Engine speed & $1200 \mathrm{rpm}$ \\
Equivalence ratio & $1(\mathrm{AFR} 14.7)$ \\
Intake pressure & $60 \mathrm{kPa}$ \\
Spark timing & $-15^{\circ} \mathrm{CA}$ aTDC \\
\hline
\end{tabular}




\subsection{High-Speed PIV}

Figure 2a also illustrates the laser setup for the application of high speed-PIV (HS-PIV) diagnostic in the optical engine. An Nd:YLF laser (Litron Lasers Ltd., LDY304) beam of $527 \mathrm{~nm}$ wavelength was converted to a $500 \mu \mathrm{m}$ thin sheet through a series of optics and then introduced into the engine combustion chamber from the bottom by reflecting off the $45^{\circ}$ mirror and then passing through the piston-top quartz window. The pulse width of the laser shot is $150 \mathrm{~ns}$ at $1 \mathrm{kHz}$ repetition rate. An area of $37 \mathrm{~mm} \times 54 \mathrm{~mm}$ in the middle of the side-view of the pent-roof, which includes the spark plug and its surrounding region was targeted as the measurement area for this study. Figure $2 \mathrm{~b}$ displays the schematics of this measurement area (right) as well as the bottom-view of the fire deck to illustrate the relative position of the laser. The PIV images were captured using a high-speed camera (Vision Research Inc., Phantom v1611) at $1280 \times 800$ resolution and the laser was operated at $7.2 \mathrm{kHz}(20 \mathrm{kHz}$ maximum) for a temporal resolution of $1^{\circ} \mathrm{CA}$ in the current engine operating condition. The time interval for two images was set to $40 \mu \mathrm{s}$. A $527 \mathrm{~nm}$ bandpass filter with band width of $20 \mathrm{~nm}$ FWHM was utilized to isolate PIV signal from other interferences. The laser and camera operations were synchronized to engine rotation by using a pulse generator. The pulse generator was triggered by the engine rotating signal and the pulse generator generated the trigger signals for laser and camera. PIV data was captured for full crank angles of 19 consecutive fired cycles due to the high-speed camera memory limitation.

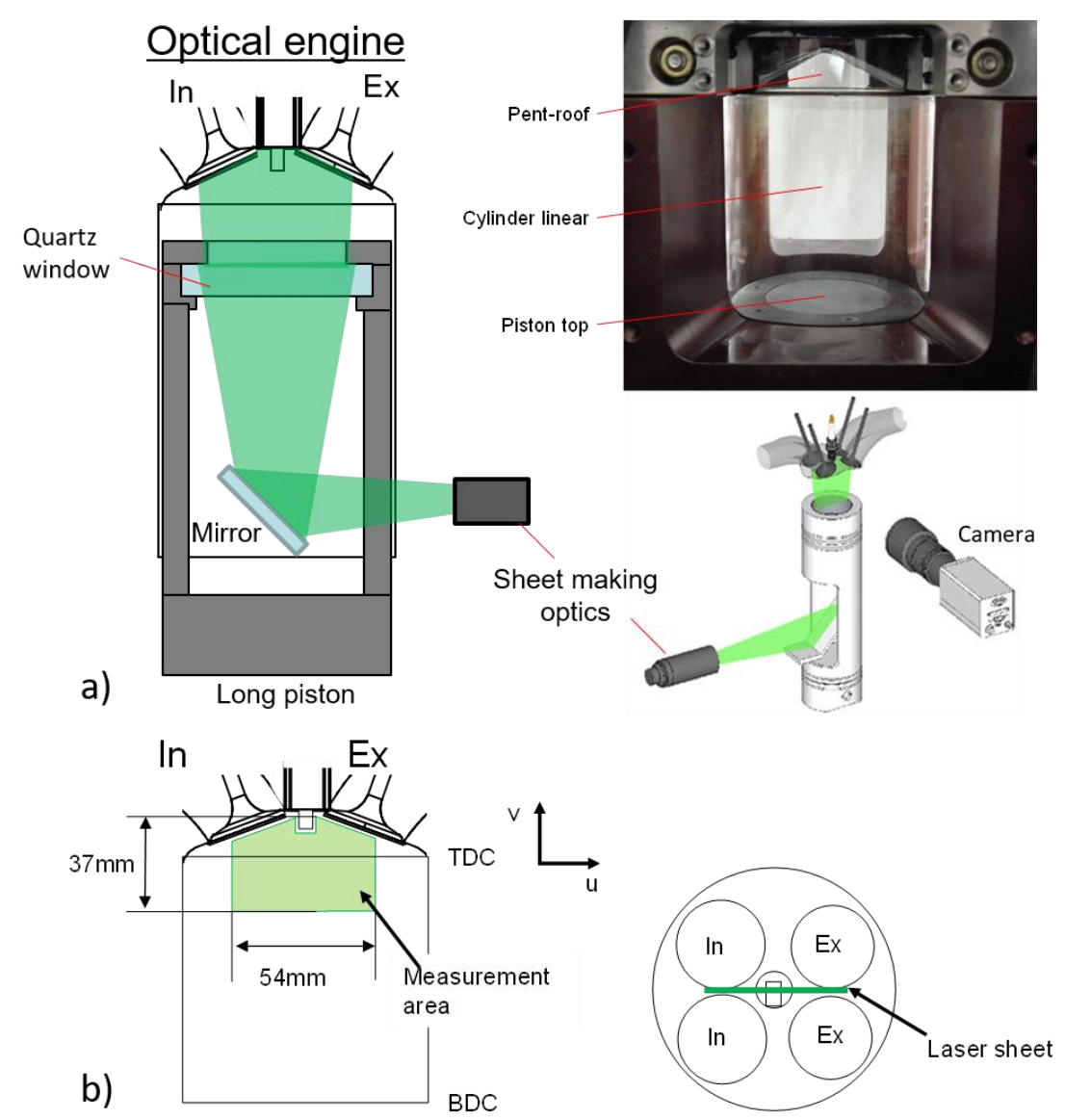

Figure 2. (a) Optical engine and Particle Image Velocimetry (PIV) set up, (b) PIV measurement area and position of the laser sheet with respect to the cylinder.

In this study, HS-PIV diagnostics was applied under engine-firing conditions which in turns introduces special challenges and difficulties. These will be described and discussed in the later sections. For optimum signal intensity with high traceability for $\mathrm{kHz}$ order, the material of the seeds 
need to be resilient to the harsh conditions of high pressure, high turbulence and high temperature inside a cylinder of a combustion engine while being inert and not affect the chemistry of combustion. As the practicability under the combustion condition was proven by previous LDV experiment at our laboratory [4], we selected a $\mathrm{SiO}_{2}$ particle with $4 \mu \mathrm{m}$ diameter as our tracer particles. The process on tuning for the best seeding amount will also be discussed in later sections. The particles in the tank were carried by the compressed air and seeded into the intake air flow upstream of the fuel injector of the optical engine to ensure the homogeneous mixing and trace to the intake air motion. Table 2 summaries the PIV setup used.

Table 2. PIV set up specifications.

\begin{tabular}{cc}
\hline Sampling frequency & $7.2 \mathrm{kHz}$ \\
Crank angle resolution & $1 \times \mathrm{CA}$ \\
Image size & $1280 \times 800(59 \times 37 \mathrm{~mm})$ \\
Spatial resolution of image & $0.046 \times 0.046 \mathrm{~mm}$ \\
Seeding particles & $\mathrm{SiO}_{2}$ \\
Measurement cycle number & $19($ consecutive $)$ \\
Interrogation area & $32 \times 32 \mathrm{px} .(1.5 \times 1.5 \mathrm{~mm})$ \\
Overlap (Duplication degree of interrogation area) & $50 \%$ \\
Spatial resolution for vector & $0.74 \times 0.74 \mathrm{~mm}$ \\
\hline
\end{tabular}

\subsection{High-Speed Flame Tomography}

Using the same HS-PIV setup, we have been able to optimize such that the burned gas region can also be identified and distinguished from the unburned region in the PIV images, which allows for flame front detection. Under combustion condition, the burned gas density and temperature will be drastically different to those of the unburned gas. The high temperature of the stoichiometric flame front can even lead to changes in the morphology of these solid seeds despite their resiliency to harsh environment. Moreover, the interaction between the PIV laser and combustion products and luminosity can also affect the laser signal intensity. As a result, these changes will be reflected in the seeding densities and scattering PIV laser intensities. Following these logics, the burned region should appear different to the unburned region. Hence, it is the gradient in intensity created that can be used for detection and identification of the burned region and hence, the flame front. To maximize the intensity gradient differences and avoid unwanted interferences from flame luminosity, a $527 \mathrm{~nm}$ bandpass-filter was placed in front of the camera. This pseudo flame tomography imaging was carried out at the same time as HS-PIV diagnostics under the same capturing procedures and operating condition.

Therefore, such HS-PIV setup allows for the simultaneous measurement of both flow-field and flame-front. The characteristics of both elements can be derived from the same captured HS-PIV image, maximizing the temporal accuracy when discussing the simultaneous relationship between flow-field and flame.

\section{Results and Discussions}

\subsection{Considerations for Diagnostics Setup}

First, the engine was installed with balancers and dampers to minimize vibrations and minimize any influences it can have on PIV arrangement. The camera and laser were also positioned on structures that well dampen from the engine vibrations. The results are confirmed to be free of vibration-induced errors which is normally seen as streaks, proving the effectiveness of this strategy. Secondly, to observe the side-view of the pent-roof area, the laser will be impinged on the cylinder head and cannot escape from the combustion cylinder, leading to possible reflections complications. As shown in Figure 3a, the reflection light can create smearing, scatters on the pent-roof and will decrease the clarity of a large portions of the measurement area. In this case, a layer of anti-reflection black paint (commercially available oily black ink) is applied onto the surface of the fire-deck and hence, the reflection light of the 
laser sheet is significantly reduced and the valid measurement area is maximized. However, it should be noted that the region around $1 \mathrm{~mm}$ away from the fire-deck of the pent-roof is still under the effect of reflection, especially at TDC.

While the stoichiometric combustion with port-fuel injection inside the S.I. engine does not produce as strong luminosity as other richer combustion seen in direct injection engine or diesel engine, the luminosity is still strong enough to create complications to the PIV signal. In fact, as seen in Figure $3 b$, the luminosity will be scattered on the seeds, especially inside the burned region. By adding a bandpass filter at the laser wavelength of $527 \mathrm{~nm}$, it is possible to remove most of the scattered light from luminosity and only capture the dominating scattering signal from the PIV laser sheet. An example PIV image demonstrates the performance of this bandpass filter during combustion is also shown in Figure $3 b$.

\section{a) Reduction of reflection light}
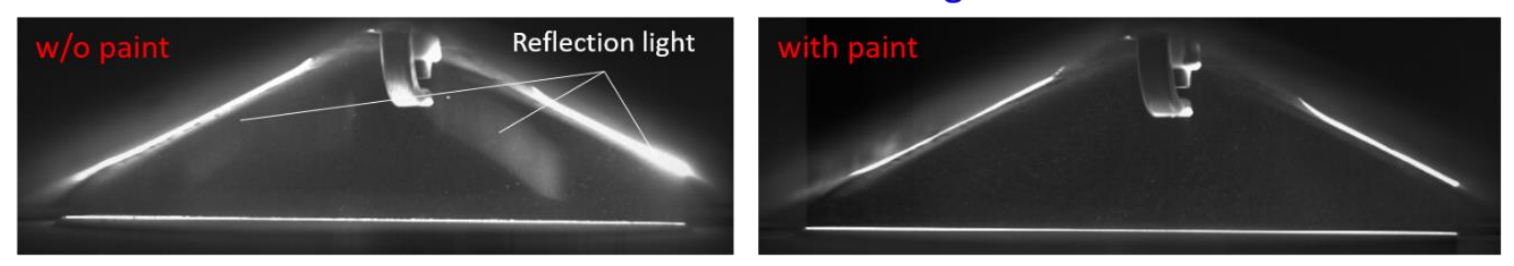

b) Elimination of flame emission

$\Rightarrow$ Bandpass filter ( $\lambda_{\text {center }}: 527 \mathrm{~nm}$, Band width: $20 \mathrm{~nm}$, Transmittance: $93 \%$ )

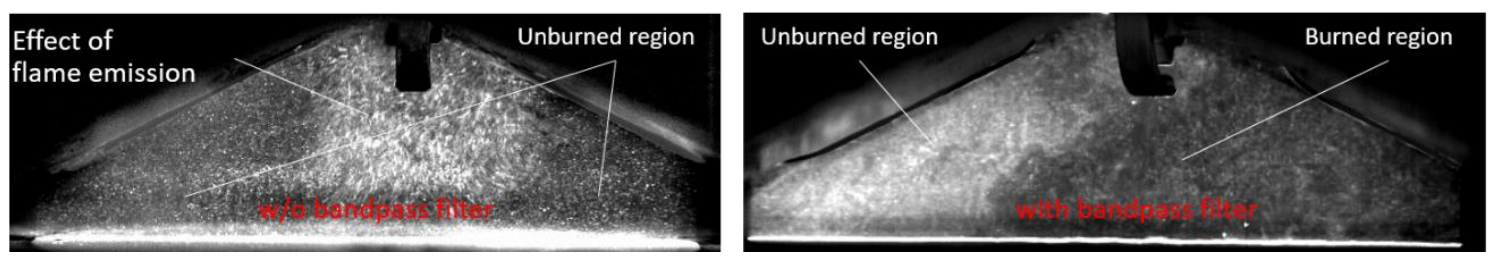

Figure 3. (a) Reducing reflection laser light during PIV measurement, (b) Avoiding the flame luminosity during combustion PIV measurement using band-pass filter.

For PIV measurement, selection of the seeding particle is crucial to achieve high quality data. As mentioned earlier, the seeds need to be inert (chemically and fluid-dynamically) and resistant to high temperature to be applicable for PIV during a combustion event in engine. We have chosen silica $\left(\mathrm{SiO}_{2}\right)$ particles in this work to ensure the flame will not burn all the particles such as the case when oil seeds were used [13]. However, to be able to distinguish between burned and unburned region from the flame analysis point of view while maintaining flow-field data from all regions, seeds materials will not be the only deciding factor. In fact, as shown in Figure 4a, depends on the amount of particles seeded into the cylinder during a firing cycle, we can either get an underexposed image where the laser scattering is not enough for PIV and flame front detection (top), an overexposed image where seeds amount was too much (middle) or only enough seeds to get PIV data but the flame cannot be detected bottom. The correct amount of seeds allows both PIV data and flame to be detected as shown in the bottom row of Figure 4a. To achieve this correct amount, the seed amount was controlled by adjusting the air flow rate for this seed supply. Once the image is confirmed, the same flow rate was kept for the rest of the experiment. Estimating the appropriate amount of seed particles in this experiment is about $1 \mathrm{~mm}^{3}$ in bulk volume per cycle. Figure $4 \mathrm{~b}$ displays the variation of the average intensity from PIV particle-scattering laser signal from BDC to TDC of a firing cycle and it demonstrated that the seeding amount can be used to monitor and measure the flow-field over the whole cycle and the intensity difference is not overwhelming so overseeding at the TDC has been avoided. It is worth noting that for this example, a spark timing of $-30^{\circ} \mathrm{CA}$ aTDC is used and the dip in PIV signal intensity seen around $-15^{\circ} \mathrm{CA}$ aTDC is most likely due to the lower density seen in the burned region. 


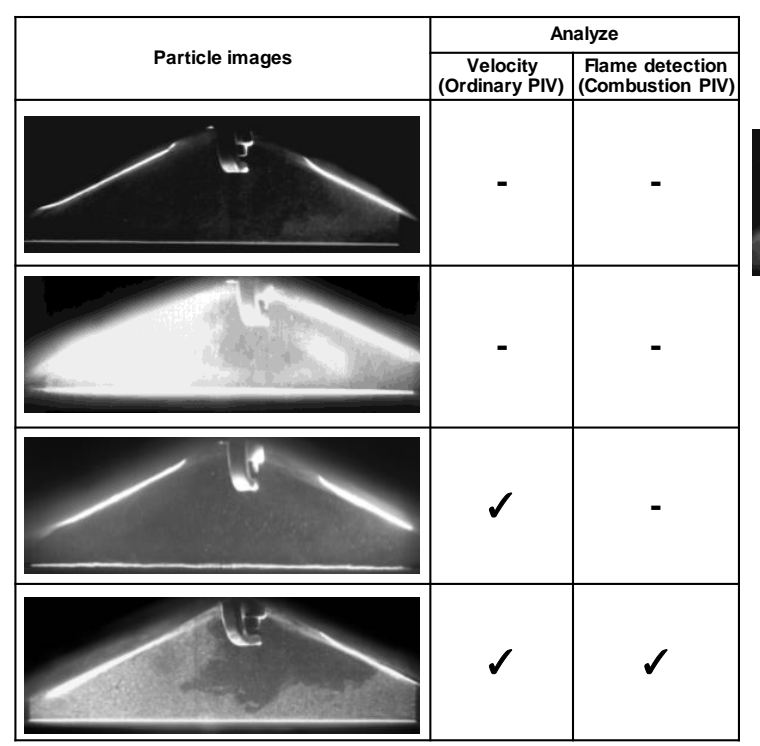

a)

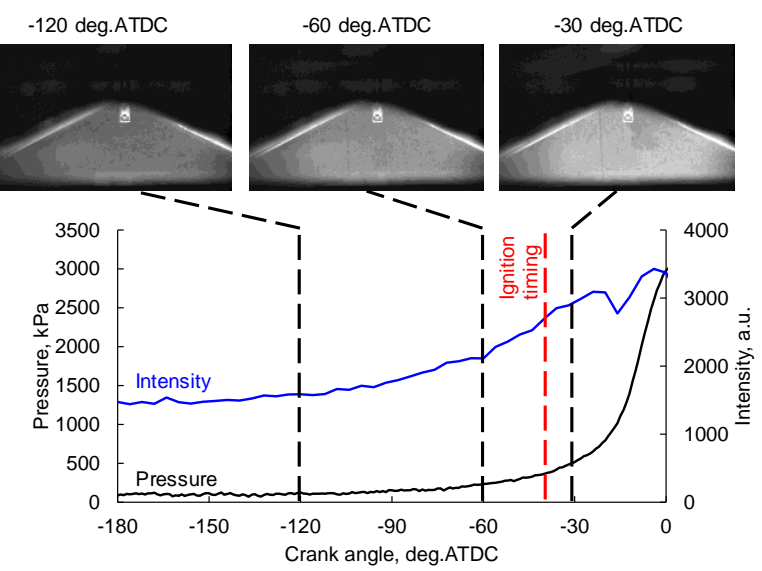

b)

Figure 4. (a) The effects of difference seeds amount on the clarity and feasibility of the information that can be measured, (b) variation of PIV intensity from BDC to TDC of a firing cycle.

\subsection{Data Processing and Validation}

\subsubsection{PIV Processing}

The instantaneous velocity field is first derived from the captured PIV images using commercial software from Dantec Dynamics. The range of the interrogation areas for considerations are $16 \times 16$, $32 \times 32$ and $64 \times 64$ at $0.046 \mathrm{~mm}$ per pixels. The vector results of the TDC flow-field at different interrogation areas are shown in Figure 5. If the normalized vector residuals $r_{0}$ calculated by the following equation exceeds the detection threshold, that vector is defined as an error vector.

$$
r_{0}=\frac{\left|U_{0}-U_{m}\right|}{r_{m}+\varepsilon}
$$

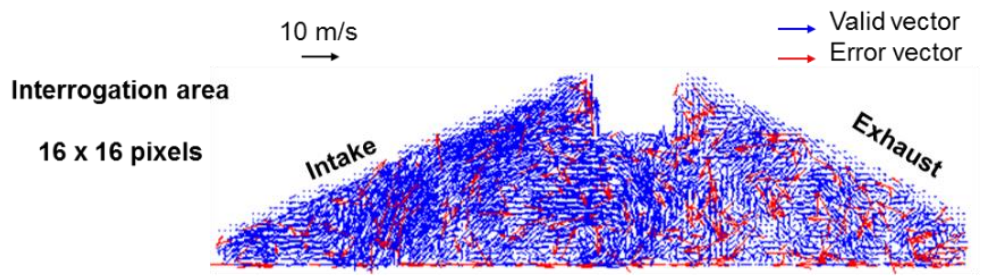

$32 \times 32$ pixels

$64 \times 64$ pixels
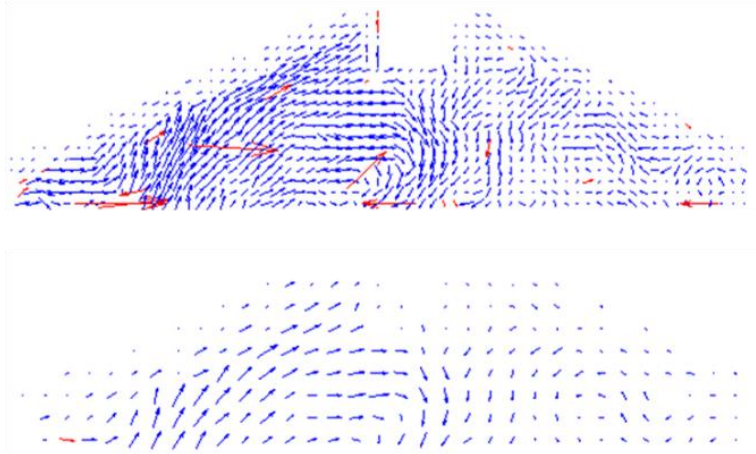

\begin{tabular}{|c|c|}
\hline Engine speed & $1200 \mathrm{rpm}$ \\
\hline $\mathrm{P}_{\text {intake }}$ & $60 \mathrm{kPa}$ \\
\hline $\mathrm{A} / \mathrm{F}$ & 14.7 \\
\hline Ignition timing & 15 deg.ATDC \\
\hline
\end{tabular}

Interrogation area, pixels

$-16 \times 16$

$-32 \times 32$

$-64 \times 64$

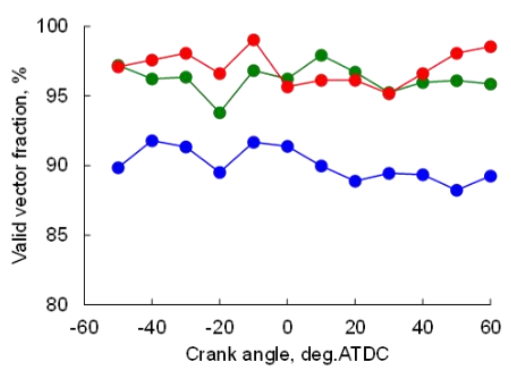

Figure 5. Validity of in-cylinder flow-field vectors from PIV processing with different interrogation areas: $16 \times 16,32 \times 32$, and $64 \times 64$ with images on left side and valid vectors \% plot on the right side. 
Here, $U_{0}$ is the displacement vector, $U_{m}$ is the median vector calculated using neighborhood vectors, $r_{m}$ is the median residual calculated using the neighborhood residuals and $\varepsilon$ is the minimum normalization level. The normalized vector residuals $r_{0}$ was calculated using $7 \times 7$ neighborhood vectors and the detection threshold was set to 1.2 . Both $32 \times 32$ and $64 \times 64$ areas allow for $\sim 95 \%$ valid vectors while the $16 \times 16$ interrogation area has more than $87 \%$ valid vectors, with most of the error vectors coming from high scattered region near piston. While $87-90 \%$ valid vectors might be enough for interpretation of the flow-field behavior, for the rest of the discussion in the current articles, we will select $32 \times 32$.

The instantaneous velocity is further processed for mean velocity, velocity fluctuations and turbulence characteristics using in-house developed MATLAB software. The most common method to derive these specific flow-field characteristics from the instantaneous velocity is to use Fourier transformation to split it into the mean velocity $(\bar{u}, \bar{v})$ and the fluctuation of velocity $\left(u^{\prime}, v^{\prime}\right)$. The instantaneous velocity $(u, v)$ and turbulence intensity are described as following equations.

$$
\begin{gathered}
u(\theta, n)=\bar{u}(\theta, n)+u^{\prime}(\theta, n) \\
v(\theta, n)=\bar{v}(\theta, n)+v^{\prime}(\theta, n) \\
k(\theta, n)=\frac{1}{2} \sqrt{\left[u^{\prime}(\theta, n)\right]^{2}+\left[v^{\prime}(\theta, n)\right]^{2}}
\end{gathered}
$$

Here, $\theta$ is crank angle and $n$ is cycle number. While spatial filter is commonly used for PIV, high-speed PIV allows the use of temporal filter. Many studies have investigated the selection of the temporal cutoff frequency for turbulent velocity estimation in internal combustion engines, which is still a relatively arbitrary process. In this study, we selected four points in the important regions of the measurement area, with three points $\mathrm{A}, \mathrm{B}$, and $\mathrm{C}$ surrounding the spark plug and point $\mathrm{D}$ near the squish area to assess the derived temporal cutoff frequency at different spatial location. The power spectrum calculated from fast Fourier transform at the four selected measurement points is shown in Figure 6 . The power spectrum was calculated from the instantaneous velocity of each 19 cycle, then the ensemble-averaged power spectrum was obtained. Around the frequency of $300 \mathrm{~Hz}$, all power spectra have an inflection point which indicate that the variability characteristic of velocity changed at this frequency. For LDV measurement in the same optical engine under near engine operating condition, the inflection point in the power spectrum was also around $300 \mathrm{~Hz}$ [4]. Therefore, the cutoff frequency of this engine operating condition has been selected to be $300 \mathrm{~Hz}$.
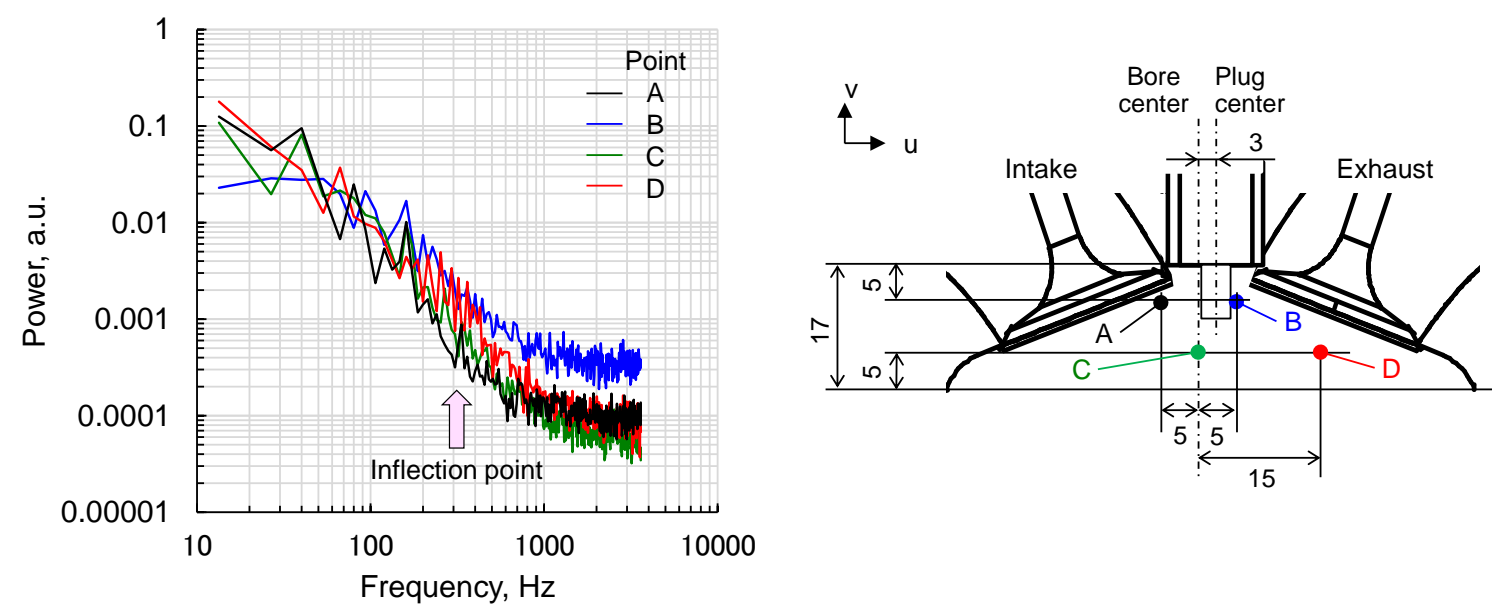

Figure 6. The power spectrum of the instantaneous velocity from PIV of different points in the measurement area. 
Due to the existence of the flame during combustion PIV application inside operating engine, the propagation of the flame could affect the seed particles by agglomeration or melting/burning of the particles and hence the velocity measured from PIV processing. To assess this potential issue, we took a PIV image during the flame developing period and analyze the velocity across the flame front. Figure 7 displays the PIV image as well as the processed information for the velocity. The difference in intensity between the burned and unburned region is quite obvious: the top right of the figure shows the intensity along a line drawn horizontally across the burned and unburned region (the line is shown in dashed white line on the image top left of the figure) and the intensity is shown to be distinctively lower in the burned region compared to the unburned region. The intensity transition between burned and unburned region is also a sharp and steep rise which indicates the error in the detected flame front will be quite low ( \pm 10 pixels, which is $\pm 0.5 \mathrm{~mm}$ ). To estimate the error in velocity due to the flame front movement, an assessment of the velocity across the flame front at various interrogation area is carried out. As the interrogation area gets smaller, the less seed particles will be tracked and if the flame front affects the seeds movement, discrepancy with larger interrogation area that cover more than the flame front. The results were plotted as shown in bottom left; all the trends were similar with different interrogation area which see a smooth transition of velocity field across the flame front. This also suggests the unburned region contains enough valid particles for PIV analysis.
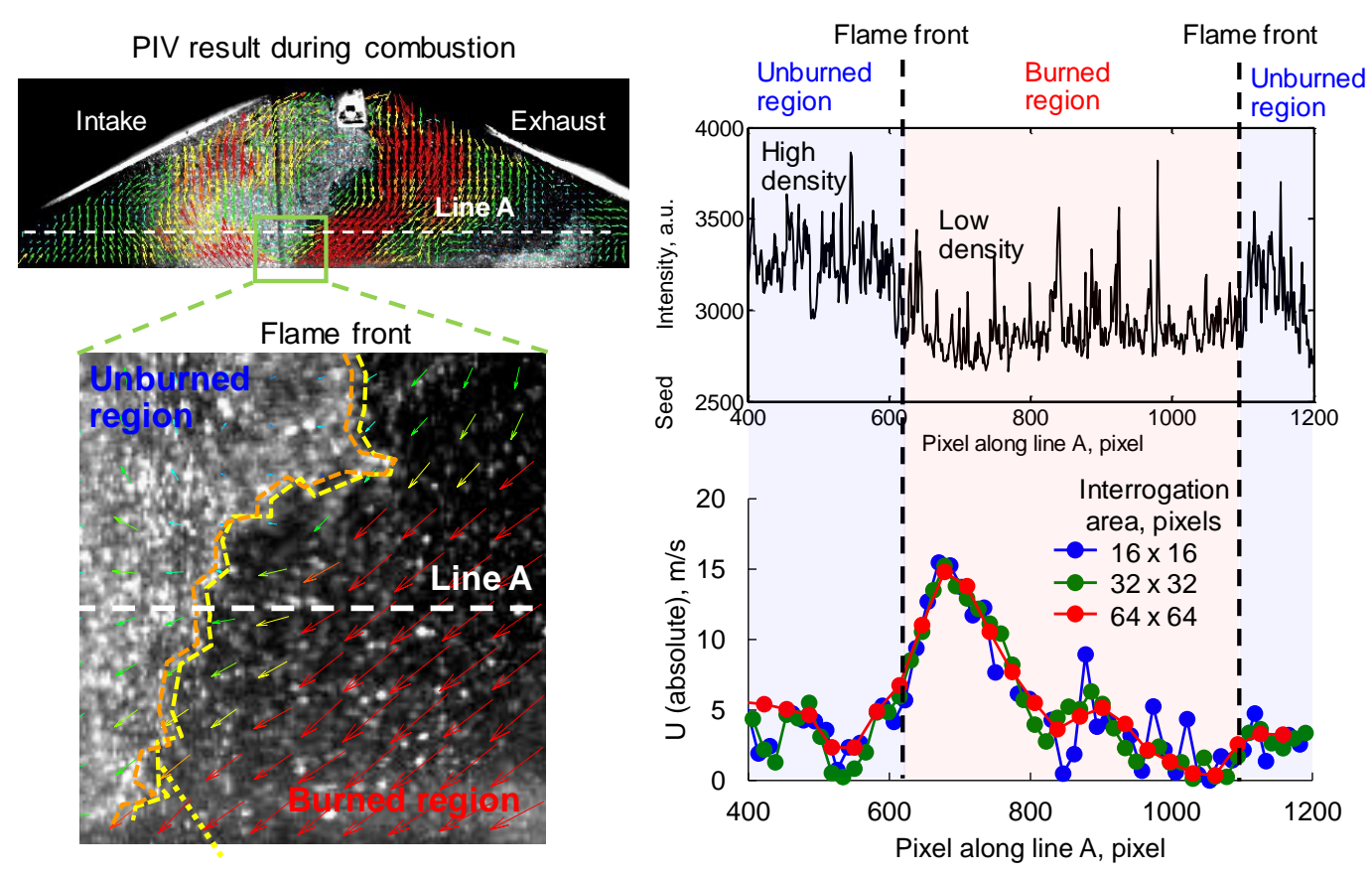

Figure 7. Effects of the flame front on derived velocity from combustion PIV at the flame front. PIV image and schematics of the analysis (left) and plots of the intensity across the measurement area on one line as well as the velocity calculated from different interrogation area (right).

\subsubsection{Flame Analysis}

The image processing steps in the algorithm for flame front detection and estimation is shown by an example at TDC $\left(15^{\circ} \mathrm{CA}\right.$ after Ignition Timing) in Figure 8 . This flame front extraction process involves the use of both automated, in-house developed algorithm and manual visual inspections of the captured images. The region bounded by the piston and the pent-roof is selected as the area of interest. First, the images are inverted and background subtraction is applied. A combination of median and Gaussian filters is then applied to eliminate artefacts due to laser scattering effects from PIV seeds. An appropriate image intensity range and results of filtering is verified by visual inspections and binary conversion using most appropriate threshold is finally applied to extract the flame front. The derived flame front is once again confirmed via visual inspections to eliminate obvious errors due 
to laser intensity fluctuations. The resulted flame front is used to derive the projected flame area, the flame centroids in the vertical plane, the equivalent flame radius $\mathrm{R}$ and global flame-growth speed $\mathrm{dR} / \mathrm{dt}$. Here, the flame centroids are defined as the position of the centroids of the burned region. The equivalent flame radius $\mathrm{R}$ is defined as the radius of a circle having the same area as the burned area. The global flame-growth speed $\mathrm{dR} / \mathrm{dt}$ is calculated from the difference of equivalent flame radius between two time points. The accuracy of the burned region detection and flame front derivation has an accuracy of around $\pm 1 \mathrm{~mm}$ which correspond well to the $1.5 \mathrm{~mm}$ resolution of flow-field PIV data. An example of flame front boundary is found in the bottom of Figure 8. The flame front analysis will be limited to the early flame period from the first detected signal to when the flame completely fills the measurement area and pent roof.

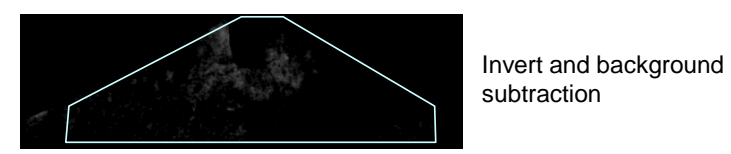

Display range optimized and boost
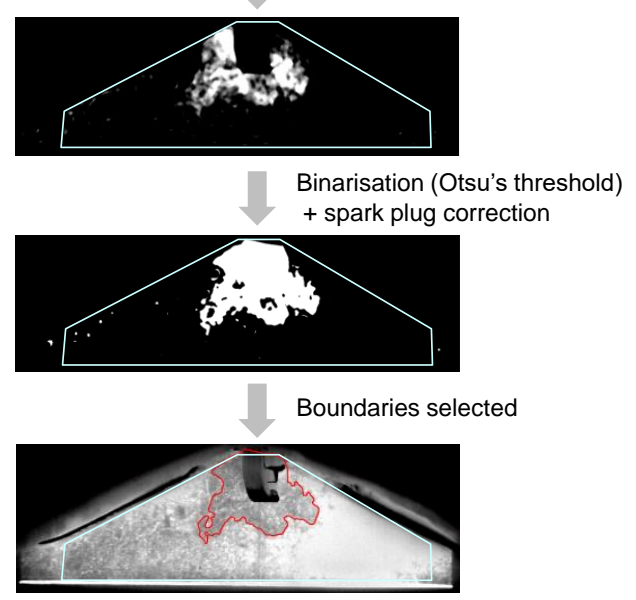

Figure 8. Image processing steps to extract the flame front from the high-speed PIV image.

\subsection{Differences Between Firing and Motoring}

Besides firing engine operation, high-speed PIV is also applied when the engine was operated in motoring mode without combustion. The PIV results were compared between firing and motoring to identify changes in the flow-field when there is a combustion event. One representative cycle out of the 19 tested cycles for each firing and motoring condition were chosen; the flow velocity of the two conditions were shown in Figure 9 and the turbulence intensity were shown in Figure 10. For brevity, images were shown in $10^{\circ} \mathrm{CA}$ timing increments, from $-45^{\circ} \mathrm{CA}$ aTDC to $25^{\circ} \mathrm{CAaTDC}$. From Figure 9, it can be seen that the flow-field between motoring and firing were not very different prior to the ignition timing $\left(-15^{\circ} \mathrm{CA}\right.$ aTDC) and the differences can be attributed to cyclic variations. The vortices centers are located more centrally in the pent roof which makes the flow across the spark plug stronger. After ignition, the flame boundary in the firing cycle is overlaid on top of the images, which can be seen from $-5^{\circ} \mathrm{CA}$ aTDC onward. During this phase, significant differences between and firing and motoring flow-field can be observed, suggested strong effect of the flame on the dynamics of the unburned region. While in the motoring cycle, the strength of the flow-field is significantly diminished, the existing tumble flow continues to exist and even enhanced by the propagating flame. The flame first propagates in the tumble flow direction and the flow-field is maintained in this direction. From $5^{\circ} \mathrm{CA}$ aTDC, the flame continues to grow with the flow: flame propagation can be seen toward the other side of the pent-roof and interestingly, the flow here is significantly enhanced. This could be because it is in the later stages of combustion where the flame has occupied a much larger volume of the combustion chamber and hence the pressure rise, the higher temperature can contribute to a 
more complicated flow-field. This is well reflected in the high turbulence intensity in the pent-roof seen in Figure 10. The flow-field maintain a high level of turbulence intensity throughout the flame development period and at the region where the flame enhanced flow is seen, a very high turbulence intensity is also found, especially close to the flame front. It is interesting that the turbulence did not decrease at any timing, even when the flame kernel just appears. This could be due to the immediate pressure and temperature rise.

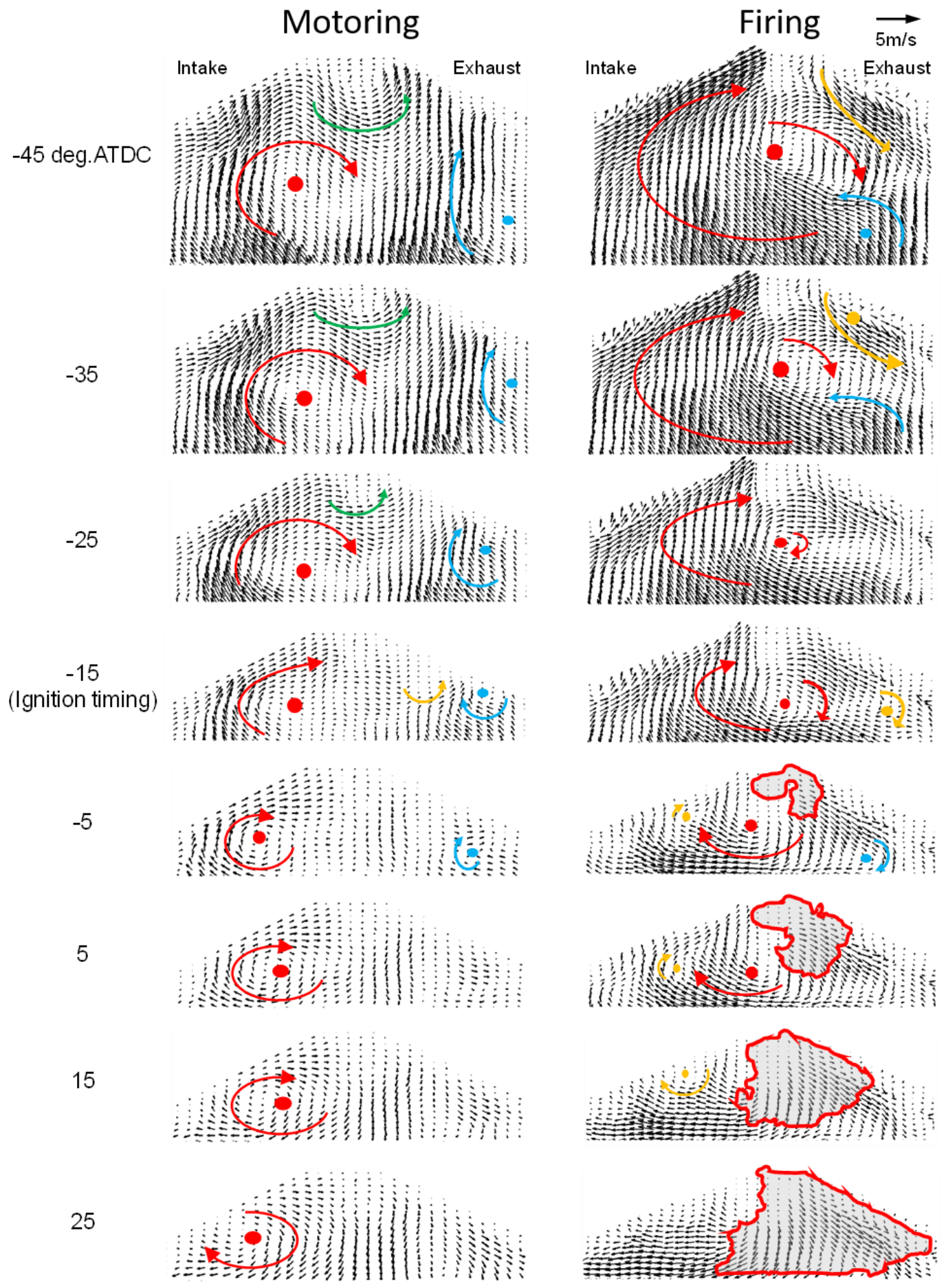

Figure 9. Mean in-cylinder flow velocity of a selected motoring cycle (left) and a selected firing cycles (right). 

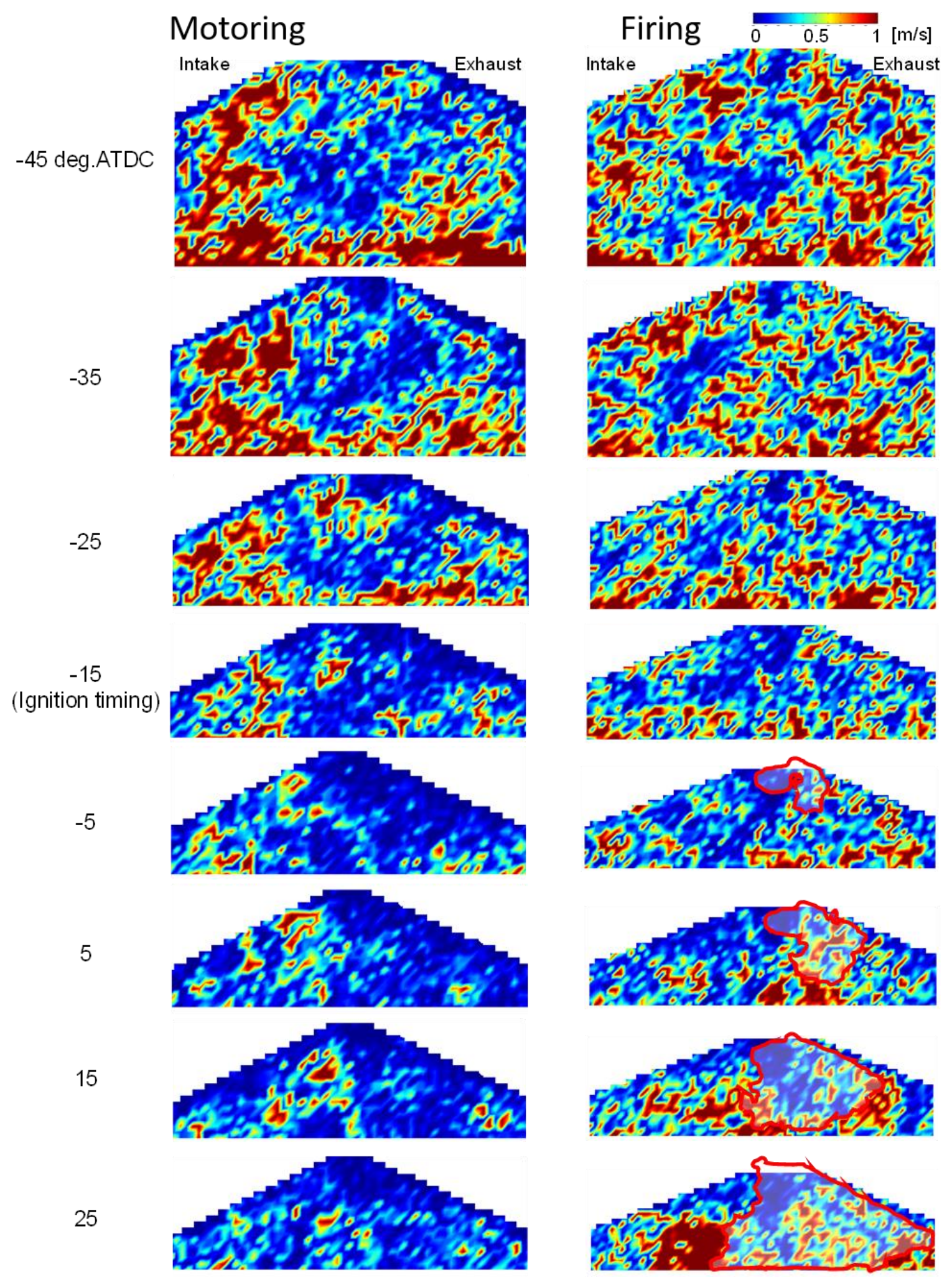

Figure 10. Turbulence intensity of a selected motoring cycle (left) and a selected firing cycles (right).

Figure 11 shows the velocity the flow at certain locations as the flame approaches and passes through them. In this case, 5 points at the same vertical distance of $2.5 \mathrm{~mm}$ to the TDC location of the piston were selected. Each point is $10 \mathrm{~mm}$ away from each other. These points were chosen as they allow the long distance away from each other while still provide a decent data size for analysis. Also, as they are close to the piston top in the period of investigation, only flow velocity in horizontal 
direction is considered. The colored dots represent the time when the flame front passes through the points. The flame crosses point D first followed by C, E, B and A which reflects its movement is influenced by the tumble direction. From the velocity plot, it is quite noticeable that as the flame passes by, the velocity of the flow achieves a local maximum. This likely suggests that as the flame approaches the flow is enhanced but quickly lost its energy as the mixture undergoes combustion.

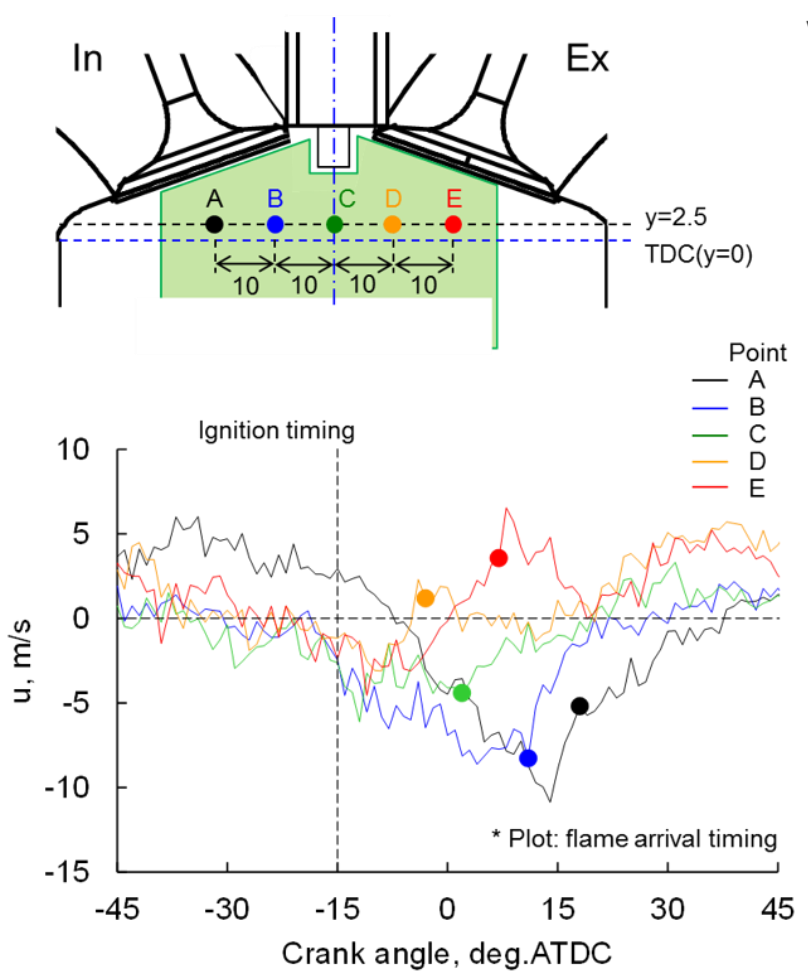

Velocity and flame front at flame arrival timing

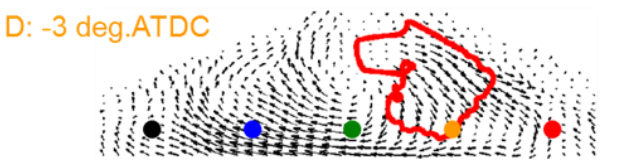

C: 2 deg.ATDC

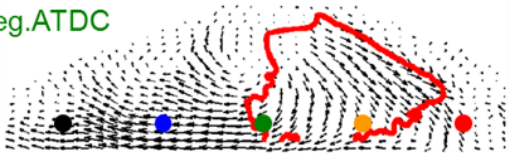

E: 7 deg.ATDC

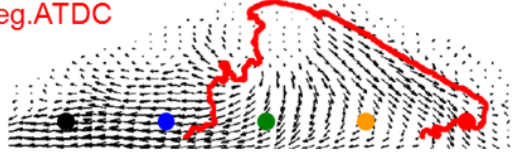

B: 11 deg.ATDC

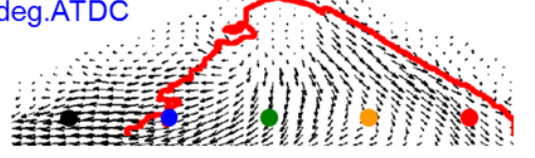

A: 18 deg.ATDC

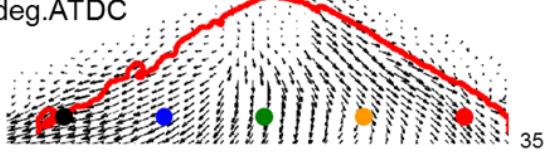

Figure 11. Velocity of the in-cylinder mixture flow at many different points as the flame front approaches and passes through those selected locations.

\subsection{Connection to Cyclic Variations and Combustion Performance}

Figure 12 displays at the top the in-cylinder pressure and the burn durations of all 19 tested firing cycles. Four cycles were selected to display the cyclic variations in flow and flame behavior. These four cycles represent different combustion performance at the same operating condition. The peak pressure of cycle $A$ is the highest because the first initial combustion (short combustion period). On the other hand, combustion pressure of cycle B is the lowest with long combustion period. In short, cycle A represents the best performing cycle, cycle B the worst performing cycles while cycles $\mathrm{C}$ and $\mathrm{D}$ are closely matching to the ensembled average. Also shown in Figure 12 is the instantaneous flow at the ignition timing of these four cycles and their flame kernel at TDC $\left(15^{\circ} \mathrm{CA}\right.$ aIT) and $10^{\circ} \mathrm{CA}$ aTDC $\left(25^{\circ}\right.$ $\mathrm{CA}$ aIT) together with the flame centroids movement over the whole investigation period. The plot of the derived flame growth speeds for the 4 cycles is also shown. All cycles have the same main tumble direction (clockwise) and the flames in cycles A, B, and C develop and propagate with the tumble direction, which can be easily observed when the centroids are plotted. Cycle D, while having the same tumble direction, the tumble center is located very far toward the squish area side of the intake and that make the flow velocity very minimal near the spark plug. As a result, the flame propagates in quite a symmetrical fashion across the spark plug axis. The centroids of this flame actually move along the spark plug axis, interestingly. Clear pattern in the flame speed in correlation with burn duration is not well observed but it is hinted that the early higher flame speed of cycle A does correspond to a faster $10 \%$ burnt duration. The variations in flame development path does not seem to have any correlation with the burnt duration. 

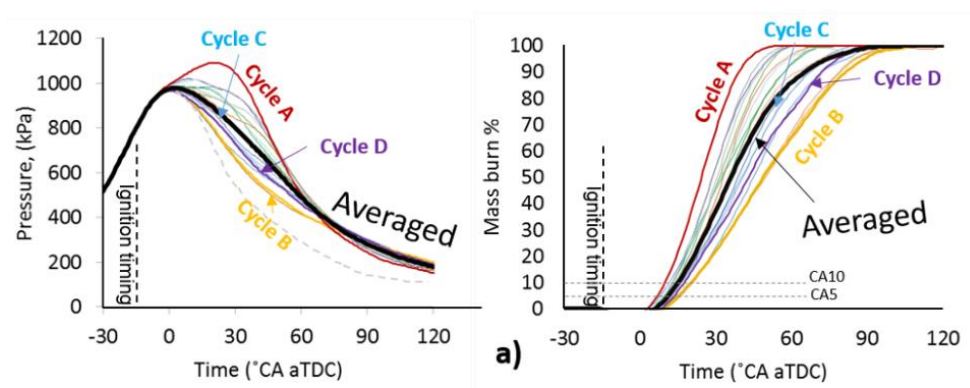

Cycle $A$
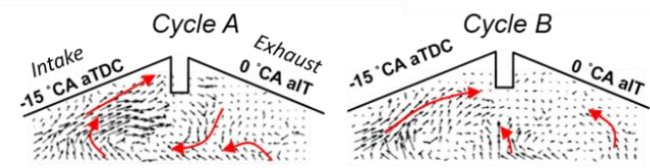

Cycle C

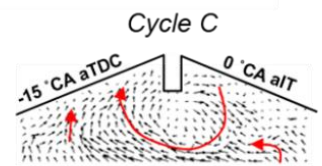

b)

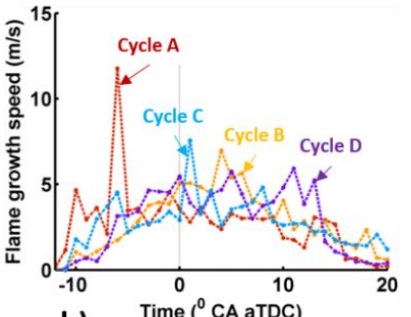

Cycle $D$
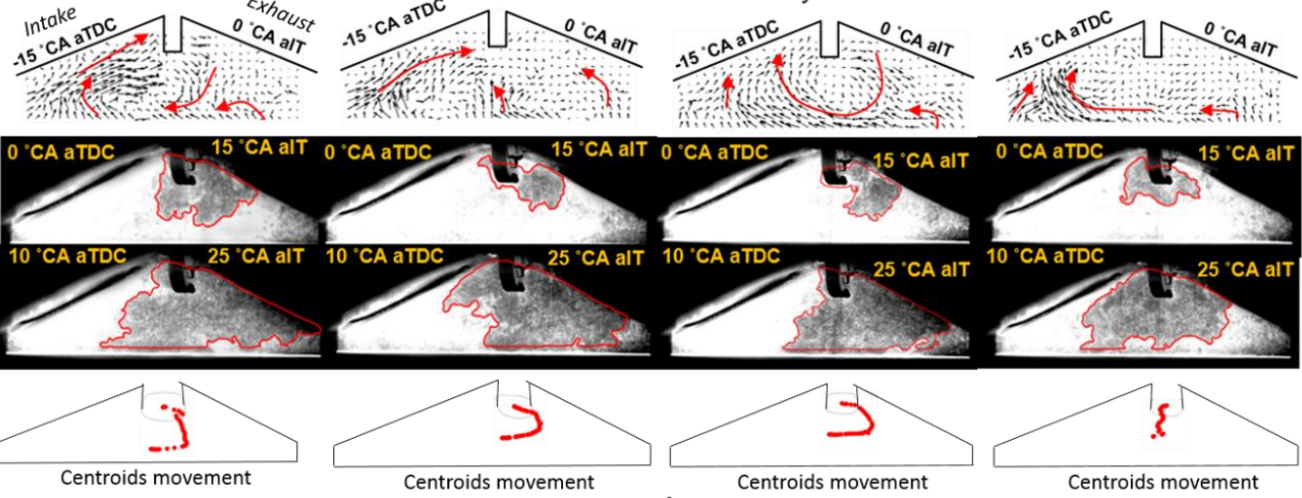

c)

Figure 12. (a) In-cylinder pressure and burnt duration of 19 tested cycles with combustion PIV, (b) the flame velocity of the four selected cycles derived from the extracted flame front and (c) flow-field vectors at the ignition timing of the four selected cycles and the flame development at $0^{\circ}$ and $10^{\circ} \mathrm{CA}$ aIT as well as the movement of the corresponding flame centroids over the whole inspected period.

Upon further analysis of the flow, the turbulence intensity near the spark plug appears to have stronger correlation with the burnt durations, with the velocity of the flow on the spark plug side that is downstream of the tumble flow results in a correlation factor of 0.56 . This seems to agree with previous research about flow across the spark plug [2].

\section{Conclusions}

A high-speed PIV set up for optical spark-ignited engine has been modified and optimized to allow not only for the measurement of flow-field characteristics but also simultaneous flame front detection and imaging. Both properties of the flow-field such as flow velocity, turbulence intensity, and flame properties such as flame area, flame speed, and wrinkleness can be derived from the same image to explore their relationship in a true simultaneous fashion. Solutions and approach to avoid and overcome interferences and challenges in applying and developing this diagnostic technique are detailed in this paper. This include the process to minimize interferences from flame luminosity and laser reflection. The processing procedures are discussed and a few validation checks were performed to ensure the technique will yield good accuracy, especially near the flame front region. After the accuracy is confirmed, the technique was then applied during firing cycles of a stoichiometric operating optical engine as well as motoring cycles of the same engine. While prior to ignition the flow-field is similar between firing and motoring case, significant differences were observed after ignition timing. The flame propagates with the global tumble direction and help maintain this flow across the pent-roof area. It also enhances flow and turbulence intensity in flow region near the flame front as the combustion enters later stages and the flame occupies a larger portion of the pent-roof. In terms of cyclic variations, there seems to be no correlation between flame shape and propagation path with burning speed. However, there is a correlation between the flow across the spark plug with burning durations as well as flame propagation path. Additionally, this relatively simple high-speed PIV setup also has a lot of potential in combining with other diagnostics to capture other combustion species, 
mixture fractions as well as other important and influential processes which will help expanding the knowledge base for advance engine design and development.

Author Contributions: Conceptualization, Y.I.; Data curation, T.F.; Writing—original draft, M.K.L; Writingreview \& editing, A.N.

Funding: This research received no external funding.

Conflicts of Interest: The authors declare no conflict of interest.

\section{References}

1. Nogawa, S.; Nataka, K.; Mohammadi, A. Effect of ignition system on combustion. In Proceedings of the 1st International Conference: Advanced Ignition System for Gasoline Engines, Berlin, Germany, 12-13 November 2012.

2. Le Coz, J. Cycle-to-Cycle Correlations between Flow Field and Combustion Initiation in an S.I. Engine; SAE Technical Paper 920517; SAE International: Warrendale, PA, USA, 1992; p. 15.

3. Abdel-Gayed, R.G.; Bradley, D.; Lawes, M. Turbulent Burning Velocities: A General Correlation in Terms of Straining Rates. Proc. R. Soc. Lond. A. 1987, 414, 389. [CrossRef]

4. Nishiyama, A.; Furui, T.; Ikeda, Y. Development of M12 Type Plug-in LDV Probe for Evaluation of Flow Field near Spark Location in SI Engine. In Proceedings of the 17th International Symposium on Applications of Laser Techniques of Fluid Mechanics, Lisbon, Portugal, 7-10 July 2014.

5. Ikeda, Y.; Nishiyama, A.; Furui, T.; Wachi, Y. PIV/LDV combination for optimum turbulence generation scheme to spark ignition in wide operating condition of SI engine. In Proceedings of the 16th International Symposium on Applications of Laser Techniques to Fluid Mechanics, Lisbon, Portugal, 9-12 July 2012.

6. Okura, Y.; Segawa, M.; Onimaru, H.; Urata, Y.; Tanahashi, M. Analysis of in-cylinder flow for a boosted GDI engine using high-speed particle image velocimetry. In Proceedings of the 17th International Symposium on Applications of Laser Techniques to Fluid Mechanics, Lisbon, Portugal, 7-10 July 2014.

7. Sick, V. High speed imaging in fundamental and applied combustion research. Proc Comb. Inst. 2013, 34, 3509-3530. [CrossRef]

8. Voisine, M.; Thomas, L.; Boree, J.; Rey, P. Spatio-temporal structure and cycle to cycle variations of an in-cylinder tumbling flow. Exp. Fluids 2011, 50, 1393-1407. [CrossRef]

9. Chi, T.; Zhai, G.; Kook, S.; Chan, Q.; Hawkes, E. Application of LED-based thermographic phosphorescent technique to diesel combustion chamber walls in a pre-burn-type optical constant-volume vessel. Exp. Fluids 2019, 60, 58. [CrossRef]

10. Clark, L.; Kook, S.; Chan, Q.; Hawkes, E. Multiple Injection Strategy Investigation for Well-Mixed Operation in an Optical Wall-Guided Spark-Ignition Direct-Injection (WG-SIDI) Engine through Flame Shape Analysis; SAE Technical Paper 2016-01-2162; SAE International: Warrendale, PA, USA, 2016; p. 12.

11. Clark, L.; Kook, S.; Chan, Q.; Hawkes, E. Influence of Injection Timing for Split-Injection Strategies on Well-Mixed High-Load Combustion Performance in an Optically Accessible Spark-Ignition Direct-Injection (SIDI) Engine; SAE Technical Paper 2017-01-0657; SAE International: Warrendale, PA, USA, 2017; p. 11.

12. Peterson, B.; Reuss, D.L.; Sick, V. High-speed imaging analysis of misfires in a spray-guided direct injection engine. Proc. Comb. Inst. 2011, 33, 3089-3096. [CrossRef]

13. Mounaïm-Rousselle, C.; Landry, L.; Halter, F.; Foucher, F. Experimental characteristics of turbulent premixed flame in a boosted spark-ignition engine. Proc. Comb. Inst. 2013, 34, 2941-2949. [CrossRef]

14. Aleiferis, P.G.; Behringer, M.K. Flame front analysis of ethanol, butanol, iso-octane and gasoline in a spark-ignition engine using laser tomography and integral length scale measurement. Combust. Flame 2015, 162, 4371-4674. [CrossRef]

15. Le, M.K.; Furui, T.; Nishiyama, A.; Ikeda, Y. Application of High-Speed PIV Diagnostics for Simultaneous Investigation of Flow Field and Spark Ignited Flame inside an Optical SI Engine. SAE Int. J. Eng. 2017, 10, 917-927. [CrossRef]

(C) 2019 by the authors. Licensee MDPI, Basel, Switzerland. This article is an open access article distributed under the terms and conditions of the Creative Commons Attribution (CC BY) license (http://creativecommons.org/licenses/by/4.0/). 